\title{
Evaluation of CD4+ CD25+ FoxP3+ Regulatory T cells and FoxP3 and CTLA-4 gene Expression in Patients wwith Newly Diagnosed Tuberculo- sis in Northeast of Iran
}

\author{
Roghayeh Ghazalsofala ${ }^{1}$; Seyed Abdolrahim Rezaee ${ }^{1}$; Houshang Rafatpanah ${ }^{2}$; Rosita \\ Vakili ${ }^{1}$; Kiarash Ghazvini ${ }^{3}$; Fatemeh Heidarnejad ${ }^{1}$; Somaye Sobhani ${ }^{1}$; Narges Valizadeh ${ }^{1}$; \\ Marayam Azami ${ }^{4}$; Marzieh Rahimzadegan ${ }^{5}$; Amir Asnaashari ${ }^{4, *}$ \\ ${ }_{1}^{1}$ Inflammation and Inflammatory Diseases Research Center, Mashhad University of Medical Sciences, Mashhad, IR Iran \\ ${ }_{3}^{2}$ Rheumatic Diseases Research Center, Mashhad University of Medical Sciences, Mashhad, IR Iran \\ ${ }^{3}$ Antimicrobial Resistance Research Center, Mashhad University of Medical Sciences, Mashhad, IR Iran \\ ${ }_{5}^{4}$ Chronic Obstructive Pulmonary Disease Research Center, Mashhad University of Medical Sciences, Mashhad, IR Iran \\ ${ }^{5}$ Infection Diseases Department, Mashhad University of Medical Sciences, Mashhad, IR Iran \\ ${ }^{*}$ Corresponding author: Amir Asnaashari, Chronic Obstructive Pulmonary Disease Research Center, Mashhad University of Medical Sciences, Mashhad, IR Iran. Tel/Fax: + 98-38002376, \\ E-mail:AsnaashariAM@mums.ac.ir
}

Received: June 3, 2014; Revised: June 8, 2014; Accepted: August 2, 2014

\begin{abstract}
Background: Tuberculosis (TB) is the world's second most common infectious disease after Human Immunodeficiency Virus Infection/ Acquired Immunodeficiency Syndrome (HIV/AID) and the most frequent cause of mortality especially in developing countries. T regulatory (Treg) cells, which have suppressive activity and express forkhead winged-helix family transcriptional repressor p3 (FoxP3), suppress the immune responses against pathogens such as Mycobacterium tuberculosis. There are controversial results regarding the role of FoxP3 expressing cells in the blood of patients with TB.

Objectives: The aim of this study was to evaluate the frequency CD4+CD25+ Treg cells, and FoxP3 and Cytotoxic T Lymphocyte Antigen 4 (CTLA-4) gene expressions in peripheral blood of patients with tuberculosis and patients with positive tuberculin skin test before and after Peripheral Blood Mononuclear Cells (PBMCs) activation with Purified Protein Derivative (PPD).

Patients and Methods: In this cross-sectional study, Peripheral Mononuclear Cells (PBMCs) were isolated from peripheral blood of 29 patients with newly diagnosed pulmonary TB and 19 patients with positive tuberculin skin test. The PBMCs were activated with PPD for 72 hours. Activated cells were harvested, RNA was extracted and cDNA was synthesized. A real-time Taqman method was designed and optimized for evaluation of Foxp3 gene expression and SYBR Green method was used and optimized for evaluation of CTLA-4 gene expression. A flow cytometry analysis was used to evaluate the frequency of $\mathrm{CD} 4+\mathrm{CD} 25+$ Foxp3+ regulatoryT cells in both groups.

Results: There was no significant difference in the frequency of CD4+CD25+FoxP3+ regulatory T cells between the two groups. Expression of FoxP3 and CTLA-4 in peripheral blood of patients with newly diagnosed TB was significantly lower than the control group after and before activation with PPD.

Conclusions: The expression of FoxP3 and CTLA-4 in PBMCs of patients with newly diagnosed TB was low, which might suggest that Treg cells may be sequestered in the lungs.
\end{abstract}

Keywords: Tuberculosis; T-Lymphocytes, Regulatory; Cytotoxic T-lymphocyte associated antigen 4 (CTLA-4 Antigen)

\section{Background}

Tuberculosis (TB) is the world's second-deadliest infectious disease after Human Immunodeficiency Virus Infection/Acquired Immunodeficiency Syndrome (HIV/AID), and the most frequent cause of mortality $(1,2)$. Currently about one-third of the world's population ( 2 billion people) are infected with TB $(1,3)$. About 8 to 10 million new infectious TB cases are reported annually, of which 2.3 million lose their life each year (4). The highest incidence of TB has been reported in Asia (55\%) and Africa (30\%), which is about 700 cases per 100,000 people (5). The incidence rate of TB in Iran based on the World Health Organization (WHO) report in 2011 has been estimated to be 17 per
100,000 individuals, which has had a significant decrease compared to $1990(36 / 100,000)(6)$. Mashhad, the city located northeast of Iran, has a high prevalence of TB as it shares a border with Afghanistan and there is a high immigration of refugees to this city (7).

Human immunodeficiency virus infection increases susceptibility to TB and in 2011, about $40 \%$ of TB patients also had HIV infection $(8,9)$. Tuberculosis has many clinical manifestations and the most common form is pulmonary tuberculosis. Patients with pulmonary tuberculosis spread bacilli in aerosol and transmit their infection to other people (10). Cellular immune response is a critical component

Copyright (C) 2015, Ahvaz Jundishapur University of Medical Sciences. This is an open-access article distributed under the terms of the Creative Commons Attribution-NonCommercial 4.0 International License (http://creativecommons.org/licenses/by-nc/4.0/) which permits copy and redistribute the material just in noncommercial usages, provided the original work is properly cited. 
of protective immunity against Mycobacterium tuberculosis. It has been reported that CD4+ effector T cells, which secrete immunocompetent cytokines such as interferon gamma (IFN $\gamma$ ), have a pivotal role in elimination of $M$. tuberculosis $(9,11)$. Activation of Th1 cells is essential to control TB infection. Furthermore, IL-4 and other Th2 related markers such as IgE and IgG4 can be found frequently in patients with pulmonary tuberculosis, and the synergistic effect between TNF- $\alpha$ and IL- 4 causes disease progression and fibrosis (12). It seems that TNF- $\alpha$ and IL-4 are more effective than IL-4 alone to suppress Th1 response against $M$. tuberculosis (13). Therefore, low Th1 and high Th2 activity is associated with the failure of immune response against TB $(12,14)$. T regulatory (Treg) cells suppress immune responses against pathogens such as M. tuberculosis and express the forkhead winged-helix family transcriptional repressor p3 (FoxP3), which has suppressive activity (15).

Development and function of natural Treg ( $\mathrm{n}$ Treg) is dependent on the expression of Foxp3 (16). FoxP3 interacts with Nuclear Factor-kB (NFkB) and represses the expression of cytokines such as IL-2, IL-4 and IFN- $\gamma$, which lead to impaired cell proliferation (17). In addition, Treg cells express CTLA- 4 on their surface, which binds to CD80 and $\mathrm{CD} 86$, and has an inhibitory role on T cell activation (18). The number of cells expressing these markers has been reported to be decreased in several chronic inflammatory disorders (19-21). Nonetheless, the number of Treg cells in patients with active TB increases in peripheral blood cells (22). It has also been reported that CD4+CD25+ FoxP3+ T cells and FoxP3 mRNA increase in blood or at the site of infection in patients with active TB (23). More recently, Pang et al. demonstrated that the frequency of nTreg cells and inductive regulatory $\mathrm{T}$ cells increase in peripheral blood samples of patients with active $\mathrm{TB}$ (24). In contrast, it has been reported that the expression of Foxp3 decreases in patients with newly diagnosed TB (25). Since, only 5 - 10\% of individuals infected by TB develop active disease (2723 to 28 ), and there are controversial data regarding the role of Treg cells in TB, evaluation of these cells in infected individuals is imperative and further studies are needed to clarify the role of Treg cells in disease development.

\section{Objectives}

The aim of this study was to evaluate the frequency CD4+ CD25+ Treg cells, and FoxP3 and Cytotoxic T Lymphocyte Antigen 4 (CTLA-4) gene expressions in peripheral blood of patients with tuberculosis and patients with positive tuberculin skin test before and after Peripheral Blood Mononuclear Cells (PBMCs) activation with Purified Protein Derivative (PPD).

\section{Patients and Methods}

\subsection{Study Population}

A cross-sectional study was conducted on 29 patients with newly diagnosed pulmonary TB and 19 healthy control subjects who were referred to Ghaem Hospital, Mashhad University of Medical Sciences during September 2011 to March 2012. The diagnosis of the patients was based on TB smear positive test, positive culture, and clinical and radiological features. Subjects with a history of Bacillus Calmette-Guérin (BCG) vaccination at an early age and no history of TB were selected as the control group. The study was approved by the ethics committee (No; 86278) of Mashhad University of Medical Sciences, Mashhad, Iran and informed consent was obtained from all participants. Participants infected with HIV, human T lymphotropic virus type I (HTLV-I), Hepatitis B virus (HBV) and Hepatitis C Virus (HCV) were excluded from the study. Blood samples were collected from all patients and control groups.

\subsection{Phenotypic Analysis}

Peripheral blood mononuclear cells (PBMCs) were isolated from $10 \mathrm{~mL}$ blood samples collected in EDTA-anticoagulated tubes by standard Ficoll-Hypaque density centrifugation (Cederlane, Canada). Furthermore, CD4+| $\mathrm{CD} 25+$, the surface markers of PBMCs were stained by incubation with PE-CY5 conjugated anti-CD4+ (Ebioscience, Germany) and FITC conjugated anti-CD25+ (BD, Ebioscience, USA) at room temperature for 30 minutes. The FITCmouse IgG1, PE-mouse IgG1 and PE-CY5-mouse IgG1 (BD Ebioscience. USA) were used as isotype controls. To analyze CD4, CD25 and FoxP3 expression, cells were stained with PE-CY5 conjugated anti-CD4 (Ebioscience) and FITC conjugated anti-CD25 (BD Ebioscience); followed by intracellular staining with anti-FoxP3 staining set (BD Ebioscience, USA). After staining, the cells were analyzed by flow cytometer using the Cell Quest software (Coulter, USA). The CD4+ CD25+ lymphocyte population was gated for FoxP3 expression analysis. The percentage of CD4+ CD25+ FoxP3 T cells to total CD4+ T cells, and proportion of FoxP3 cells in CD4+ CD25+ T cells were computed for different groups.

\subsection{Gene Expression Analysis by Real-Time Poly- merase Chain Reaction}

Peripheral Blood Mononuclear Cells were washed twice by culture medium and were subjected to further analysis. The PBMCs were cultured in 12-well plates at a concentration of 1.106 in $1000 \mu \mathrm{L}$ of RPMI 1640 complete medium (Gibco, USA). The cells were activated by $0.75 \mathrm{TU} / \mathrm{ml}$ Purified Protein Derivative (PPD) (SPAN Diagnostic, India) for 72 hours. Next, activated cells were harvested and RNA extraction and cDNA synthesis was performed as follows; RNA was extracted using a TriPure Isolation Kit (Roche Co.) according to manufacturer's instructions. Treatment with DNase I followed to remove contamination. Reverse transcription reaction was performed with Revert Aid H minus First Strand cDNA Synthesis Kit (Fermentas, Germany). Reverse transcription was carried out at $42^{\circ} \mathrm{C}$ for 60 minutes followed by RT inactivation at $70^{\circ} \mathrm{C}$ for five minutes. cDNA 
was kept at $-20^{\circ} \mathrm{C}$ until analysis. Amplification was performed by Corbet Research using Quantifast SYBR Green and the Taq man detection Kit (TaKaRa, Japan). Primer and probe sequences are described in Table 1.

Polymerase chain reaction conditions by the Taqman method were as follows: holding at $95^{\circ} \mathrm{C} 10$ minutes, followed by 40 cycles of denaturation at $95^{\circ} \mathrm{C}$ for 10 seconds, and annealing and extension at $60^{\circ} \mathrm{C}$ for 45 seconds. Polymerase chain reaction conditions by SYBR Green method were as follows; holding at $95^{\circ} \mathrm{C} 10$ seconds, followed by 40 cycles of denaturation at $95^{\circ} \mathrm{C}$ for 10 seconds, and annealing and extension at $60{ }^{\circ} \mathrm{C}$ for 45 seconds. Standard curves were prepared for target and reference genes. The Rotor Gene software was used to analyze the standards and to carry out the quantifications. Relative expression level of FoxP3 and CTLA-4 mRNA in both activated and non-activated cells were normalized by $\beta 2 \mathrm{M}$, as a house keeping gene, and calculated by the $2-\Delta \Delta$ Ct method.

\subsection{Statistical Analysis}

Data was expressed as mean \pm SD. Statistical analysis for paired variables was performed with paired sample t-test. Comparisons of FoxP3 and CTLA-4 gene expression between control group and TB patients were performed using the non-parametric two-tailed Mann-Whitney Utest. The Wilcoxon matched paired t-test was used to analyze the effect of PBMCs activation with PPD on FoxP3 and CTLA- 4 gene expression, and then gene expressions before and after PBMCs activation were compared. P values of $<0.05$ were considered statistically significant. All analyses were performed using the SPSS version 20 software.

\section{Results}

\subsection{Patient Characteristics}

In this study 19 healthy controls and 29 patients with newly diagnosed pulmonary TB were enrolled. Overall, 18 males and 11 females were in the patient group. The con- trol group consisted of 14 males and five females. There was no statistically significant gender difference between the two groups $(\mathrm{P}=0.9)$. The mean age of each group was $52 \pm 4$ years for patients with TB (range 16 - 85 years) and $43 \pm 2$ years (range 30 - 68 years) for healthy controls. No significant difference existed in mean age between the two groups $(\mathrm{P}>0.05)$. Frequency of Treg cells were measured and compared between control and patient groups. In addition, expression of FoxP3 and CTLA-4 were evaluated before and after activation with PPD and compared for each group.

\subsection{The Association of CD4+CD25+ FoxP3+ T Cells Frequency With Newly Diagnosed Tuberculosis}

The frequency of CD4+ CD25+ FoxP3+ regulatory T cells in control and patient groups was evaluated to investigate whether M. tuberculosis infection is associated with CD4+ CD25+ FoxP3+ Treg expansion. The mean number of Treg cells in PBMCs of the control group was $1.57 \pm 0.1 \%$ and in the patient group was $1.5 \pm 0.1 \%$. As shown in Figure 1 no significant differences in the frequency of CD4+ $\mathrm{CD} 25+$ FoxP3 regulatory $\mathrm{T}$ cells between the control group and patients with tuberculosis was observed $(\mathrm{P}>0.05)$.

\subsection{FoxP3 mRNA Expression}

We evaluated FoxP3 gene expression in PBMCs isolated from blood samples of the control and patient groups before and after PBMCs activation with PPD. The mean FoxP3 gene expression in controls and patients before PBMCs activation was $1.4 \pm 0.2$ and $0.5 \pm 0.1$, respectively. FoxP3 mRNA expression was significantly higher in the control group compared to the patients with tuberculosis before PBMCs activation with PPD $(\mathrm{P}=0.01)$ (Figure 2$)$. The mean FoxP3 gene expression in the control and patients groups after PBMCs activation was $3.8 \pm 0.7$ and $1.1 \pm 0.2$, respectively. FoxP3 mRNA expression was significantly increased in the control group compared to patients with tuberculosis after PBMCs activation with PPD $(\mathrm{P}=0.000)$ (Figure 2)

\begin{tabular}{|c|c|c|c|}
\hline Name & Sequence $\left(5^{\prime}-3\right)$ & Accession Number & Product Length \\
\hline FoxP3 & & 001114377 & $95 \mathrm{bp}$ \\
\hline Forward & АСТАСТTСААТTТССАСАСGC & & \\
\hline Reverse & GAGTGTCCGCTGCTTCTCTG & & \\
\hline Probe & TCACCTACGCCACGTTCATCCGCT & & \\
\hline CTLA-4 & & 00521404 & 209 bp \\
\hline Forward & СТСATGTACCCATCGCCATAC & & \\
\hline Reverse & ACATAGACCCCTGTTGTAAGAGG & & \\
\hline$\beta_{\mathbf{2}} \mathbf{M}$ & & NM_004048.2 & $127 \mathrm{bp}$ \\
\hline Forward & TTGTCTTTCAGCAAGGACTGG & & \\
\hline Reverse & ССАСТTAАСТАTCTTGGGCTGTG & & \\
\hline Probe & TCACATGGTTCACACGGCAGGCAT & & \\
\hline
\end{tabular}


Figure 1. Frequency of CD4+CD25+ FoxP3+ Regulatory T Cells in Control and Patient Groups

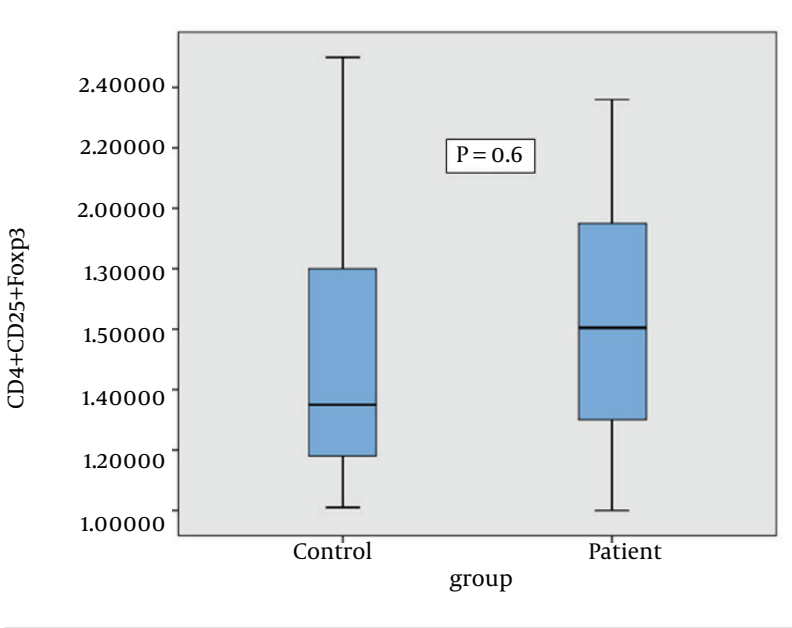

No significant differences in the frequency of cd4+ cd25+ foxp3 regulatory T cells were observed between the control group and patients with tuberculosis $(\mathrm{p}>0.05)$.

\subsection{CTLA-4 mRNA Expression}

CTLA-4 gene expression was examined in PBMCs isolated from blood samples of the control group and patients with TB before PBMCs activation with PPD. The mean CTLA-4 gene expression was $1.66 \pm 0.18$ and $0.8 \pm 0.2$ for the control and patient groups, respectively. The data revealed that CTLA-4 mRNA expression in the control group was significantly higher compared to the patient group $(\mathrm{P}=0.005)$. The mean CTLA-4 gene expression in controls and patients after PBMCs activation with PPD was $3.4 \pm$ 0.4 and $1.1 \pm 0.2$, respectively. CTLA-4 mRNA expression was significantly higher in the control group compared to patients $(\mathrm{P}=0.000)$ (Figure 3$)$

\subsection{Comparison of FoxP3 and CTLA-4 Gene Expres- sion Before and After PBMCs Activation with PPD}

FoxP3 gene expression increased after PBMCs activation with PPD compared to before PBMCs activation in both groups $(\mathrm{P}=0.001)$. CTLA-4 gene expression increased after PBMCs activation with PPD compared to before PBMCs activation in the control group $(\mathrm{P}=0.006)$. CTLA-4 expression in the patient group was not significantly different before and after PBMCs activation with PPD $(\mathrm{P}=0.2)$.

\section{Discussion}

Adaptive immune response provides long-term highlyeffective protection against pathogens. CD25+ CD4+ regulatory $\mathrm{T}$ cells play an important role in preventing immune responses to auto-antigens and are also involved in immune response to infections agents $(26,27)$. In the present study, the frequency of CD4+ CD25+ FoxP3+ Treg cells and expression of FoxP3 and CTLA-4 in peripheral blood of patients with newly diagnosed TB and the control group including patients with positive tuberculin skin test were evaluated. In contrast to some previous studies, the results of this study showed that the frequency of CD4+ CD25+ FoxP3+ Treg cells in the early stages of the disease, before treatment, is not significantly different between the two groups (28-30).

The Foxp3 transcription factor is a reliable marker of Treg cells and unlike CD25, CTLA-4, and glucocorticoidinduced tumor-necrosis-factor-receptor-related protein (GITR), FoxP3 is not upregulated in activated CD4+ CD25-T cells $(26,31)$. In TB, Th1 response is extremely down-regulated and may lead to disease progression. Furthermore,

Figure 2. Foxp3 mRNA Expression Before and After Cell Activation With PPD in Patient and Control Groups
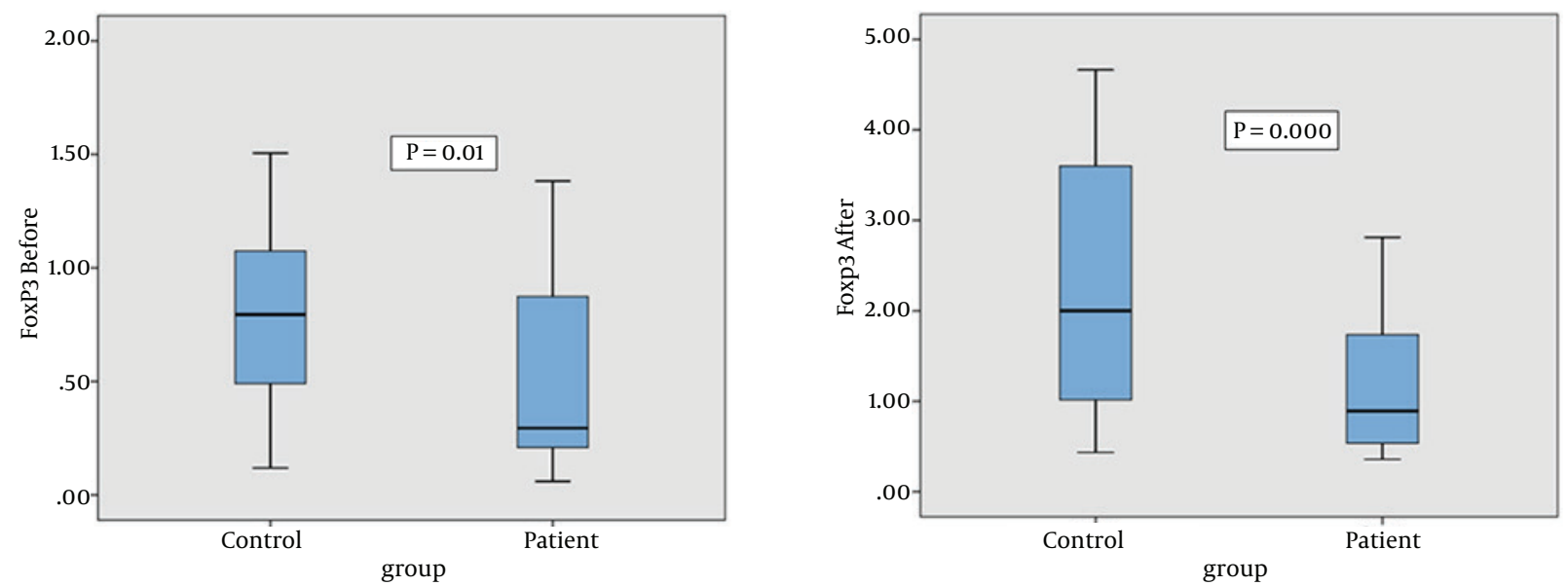

FoxP3 mRNA expression was higher in the control group compared with the patients before and after PPD activation $(\mathrm{P}=0.01, \mathrm{P}=0.000)$. 
Figure 3. CTLA-4 mRNA Expression Before and After Cell Activation with PPD in Patient and Control Groups
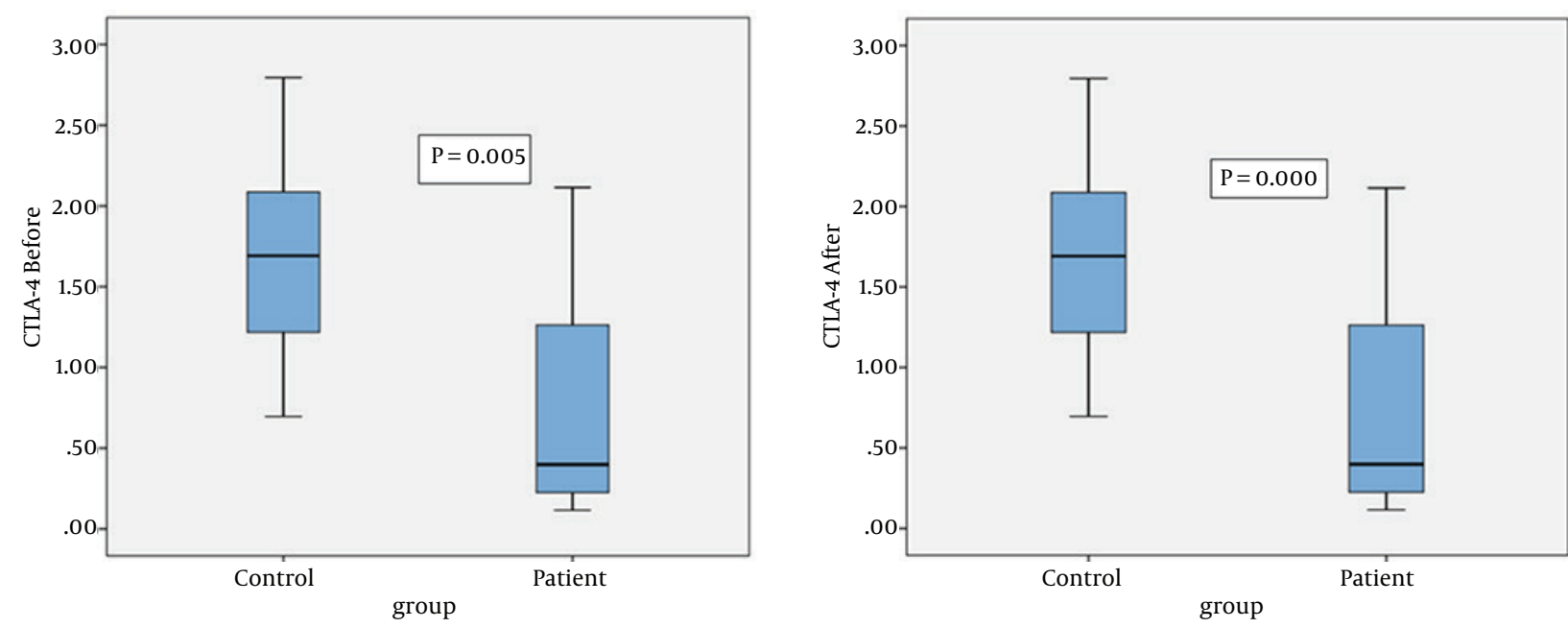

CTLA-4 mRNA expression was higher in the control group compared with patients before and after PPD activation $(\mathrm{P}=0.005, \mathrm{P}=0.000)$

in early subclinical TB, the expression of FoxP3 in peripheral blood of patients has been shown to decrease; however, when TB becomes progressive, the expression of FoxP3 is upregulated (25). Several previous studies have compared the frequency of CD4+ CD25+ FoxP3+ Treg cells in patients with active and latent $\mathrm{TB}$, and demonstrated that the percentage of Treg cells in patients with active $\mathrm{TB}$ increases and leads to the suppression of immune response and progression of chronic disease $(9,23,28)$. Moreover, increased number of inflammatory cells, especially T-cell populations (Th1/Th2/Th17/Treg cells) at the site of infection, in newly diagnosed TB patients has also been reported previously $(29,32)$.

Our results are consisted with the mentioned studies, and we could not find any differences in the frequency of CD4+ CD25+ FoxP3+ Treg cells between cases and controls, which might be because our TB patients were studied during the early stages of infection in which some of Treg cells migrate to the site of infection and therefore, result transiently reduced numbers of Treg cells in peripheral blood (25). Studies have shown that BCG induces FoxP3 mRNA expression in some mycobacteriastimulated whole blood samples, which might suggest the presence of BCG induced regulatory CD4 T cells (33). Additionally, in this study we demonstrated statistically significant increases in expression of FoxP3 and CTLA-4 in the control group compared to patients with newly diagnosed TB before and after activation with PPD. Furthermore, previous studies have shown that the expression of Foxp3 in humans is inadequate to induce T cell activity (34) and Foxp3 expression in humans correlates with suppressive activity, which is a transient property of all activated CD4+ T-cell subsets (35).

Adaptive immune response to TB is significantly delayed compared to other pathogens, suggesting that individuals, who are exposed to M. tuberculosis, show a positive tuberculin test for six weeks after exposure to $M$. tuberculosis $(36,37)$. Therefore, there were no changes in the frequency of CD4+ CD25+ FoxP3+ Treg cells in the peripheral blood of our patients, and low Foxp3 and CTLA4 expression might be due to accumulation of T cells in the patients' lungs (38). The Treg cells which display an activated phenotype such as cell surface molecules and chemokine receptors tend to accumulate in the lung (39), and this could be considered as one of the explanations for the low expression of Foxp3 and CTLA-4 in PBMCs of patients with M. tuberculosis.

It should be taken into account that during chronic infection, pathogen-specific T reg cells might arise through clonal expansion of antigen-specific cells from within the natural T reg cell population, thus it is not clear whether PPD expands M. tuberculosis-specific or non-specific Treg cells in PBMCs. Based on our results it is more likely that PPD induces non-specific T reg cells rather than $M$. tuberculosis-specific $\mathrm{T}$ reg cells, thus the expression of Foxp3 and CTLA- 4 is higher in the control group compared to patients with TB; further studies are needed to clarify this issue (40). Taken together, it seems that Treg cells in the first phase of active TB, accumulate in the primary site of infection such as lymph nodes and lungs, thus the expression of Treg markers are decreased in newly diagnosed cases. Further studies are needed to clarify the controversial data regarding Treg cells in TB.

\section{Acknowledgements}

We would like to thank all patients who participated in this study.

\section{Authors' Contributions}

Amir Asnaashari, Seyed Abdolrahim Rezaee, Houshang 
Rafatpanah and Kiarash Ghazvini Marayam Azami: designed and supervised the study. Houshang Rafatpanah, Rosita Vakili and Roghayeh Ghazalsofala: analyzed the data and wrote the paper. Roghayeh Ghazalsofala, Fatemeh Heidarnejad, Somaye Sobhani and Narges Valizadeh: performed the experiments.

\section{Funding/Support}

This study was financially supported by the Vice Chancellor of Research, Mashhad University of Medical Sciences, Mashhad, Iran.

\section{References}

1. Sharma SK, Liu JJ. Progress of DOTS in global tuberculosis control. Lancet. 2006;367(9514):951-2.

2. World Health Organization . Tuberculosis. 2013. Available from: http://www.who.int/mediacentre/factsheets/fs104/en/.

3. Bello AK, Njoku CH. Tuberculosis: current trends in diagnosis and treatment. Niger J Clin Pract. 2005;8(2):118-24.

4. Figueiredo AA, Lucon AM. Urogenital tuberculosis: update and review of 8961 cases from the world literature. Rev Urol. 2008;10(3):207-17.

5. Schmidt CW. Linking TB and the environment: an overlooked mitigation strategy. Environ Health Perspect. 2008;116(11):A478-85.

6. World Health Organization.. Global tuberculosis control.2011. Available from: http://whqlibdoc.who.int/publications/2011/9789241564380_ eng.pdf.

7. Derakhshan M, Safdari H, Sadeghi A, Ghazvini K, Mohammadi S. Prevalence of Mycobacterium tuberculosis in the samples referred to the tuberculosis research laboratory in Mashhad Ghaem Hospital during 2005-2006. Iran J Microbiol . 2009;1(3):20-2.

8. Pawlowski A, Jansson M, Skold M, Rottenberg ME, Kallenius G. Tuberculosis and HIV co-infection. PLoS Pathog. 2012;8(2)

9. Stenger S, Modlin RL. T cell mediated immunity to Mycobacterium tuberculosis. Curr Opin Microbiol.1999;2(1):89-93.

10. Marin ND, Paris SC, Velez VM, Rojas CA, Rojas M, Garcia LF. Regulatory $\mathrm{T}$ cell frequency and modulation of IFN-gamma and IL-17 in active and latent tuberculosis. Tuberculosis (Edinb). 2010;90(4):252-61.

11. Flynn JL, Chan J. Immunology of tuberculosis. Annu Rev Immunol. 2001;19:93-129.

12. Lienhardt C, Azzurri A, Amedei A, Fielding K, Sillah J, Sow OY, et al Active tuberculosis in Africa is associated with reduced Th1 and increased Th2 activity in vivo. Eur J Immunol. 2002;32(6):1605-13.

13. Rook GA, Hernandez-Pando R, Dheda K, Teng Seah G. IL-4 in tuberculosis: implications for vaccine design. Trends Immunol. 2004;25(9):483-8.

14. Holscher C, Holscher A, Ruckerl D, Yoshimoto T, Yoshida H, Mak $\mathrm{T}$, et al. The IL-27 receptor chain WSX-1 differentially regulates antibacterial immunity and survival during experimental tuberculosis. J Immunol. 2005;174(6):3534-44.

15. Chiacchio T, Casetti R, Butera O, Vanini V, Carrara S, Girardi E, et al. Characterization of regulatory T cells identified as CD4(+) CD25(high)CD39(+) in patients with active tuberculosis. Clin Exp Immunol. 2009;156(3):463-70.

16. Yi H, Zhen Y, Jiang L, Zheng J, Zhao Y. The phenotypic characterization of naturally occurring regulatory CD4+CD25+ T cells. Cell Mol Immunol. 2006;3(3):189-95.

17. Vrabelova Z, Hrotekova Z, Hladikova Z, Bohmova K, Stechova K, Michalek J. CD 127-and FoxP3+ expression on CD25+CD4+ T regulatory cells upon specific diabetogeneic stimulation in high-risk relatives of type 1 diabetes mellitus patients. Scand J Immunol. 2008;67(4):404-10.

18. Sakaguchi S, Wing K, Onishi Y, Prieto-Martin P, Yamaguchi T Regulatory T cells: how do they suppress immune responses? Int
Immunol. 2009;21(10):1105-11.

19. Verhagen J, Akdis M, Traidl-Hoffmann C, Schmid-Grendelmeier P Hijnen D, Knol EF, et al. Absence of T-regulatory cell expression and function in atopic dermatitis skin. J Allergy Clin Immunol. 2006;117(1):176-83.

20. Lan RY, Cheng C, Lian ZX, Tsuneyama K, Yang GX, Moritoki Y, et al Liver-targeted and peripheral blood alterations of regulatory $\mathrm{T}$ cells in primary biliary cirrhosis. Hepatology. 2006;43(4):729-37.

21. Park O, Grishina I, Leung PS, Gershwin ME, Prindiville T. Analysis of the Foxp3/scurfin gene in Crohn's disease. Ann N Y Acad Sci. 2005;1051:218-28.

22. Shafiani S, Tucker-Heard G, Kariyone A, Takatsu K, Urdahl KB. Pathogen-specific regulatory $\mathrm{T}$ cells delay the arrival of effector $\mathrm{T}$ cells in the lung during early tuberculosis. J Exp Med. 2010;207(7):1409-20.

23. He XY, Xiao L, Chen HB, Hao J, Li J, Wang YJ, et al. T regulatory cells and Th1/Th2 cytokines in peripheral blood from tuberculosis patients. Eur J Clin Microbiol Infect Dis. 2010;29(6):643-50.

24. Pang H, Yu Q, Guo B, Jiang Y, Wan L, Li J, et al. Frequency of regulatory T-cells in the peripheral blood of patients with pulmonary tuberculosis from shanxi province, china. PLoS One. 2013;8(6).

25. Burl S, Hill PC, Jeffries DJ, Holland MJ, Fox A, Lugos MD, et al FOXP3 gene expression in a tuberculosis case contact study. Clin Exp Immunol. 2007;149(1):117-22.

26. Fontenot JD, Rasmussen JP, Williams LM, Dooley JL, Farr AG Rudensky AY. Regulatory T cell lineage specification by the forkhead transcription factor foxp3. Immunity. 2005;22(3):329-41.

27. de Almeida AS, Fiske CT, Sterling TR, Kalams SA. Increased frequency of regulatory $\mathrm{T}$ cells and $\mathrm{T}$ lymphocyte activation in persons with previously treated extrapulmonary tuberculosis. Clin Vaccine Immunol. 2012;19(1):45-52.

28. Chen X, Zhou B, Li M, Deng Q, Wu X, Le X, et al. CD4(+)CD25(+) FoxP3(+) regulatory $\mathrm{T}$ cells suppress Mycobacterium tuberculosis immunity in patients with active disease. Clin Immunol. 2007;123(1):50-9.

29. Ye ZJ, Zhou Q, Du RH, Li X, Huang B, Shi HZ. Imbalance of Th17 cells and regulatory T cells in tuberculous pleural effusion. Clin Vaccine Immunol. 2011;18(10):1608-15.

30. Guyot-Revol V, Innes JA, Hackforth S, Hinks T, Lalvani A. Regulatory $\mathrm{T}$ cells are expanded in blood and disease sites in patients with tuberculosis. Am J Respir Crit Care Med. 2006;173(7):803-10.

31. Roberts T, Beyers N, Aguirre A, Walzl G. Immunosuppression during active tuberculosis is characterized by decreased interferongamma production and CD25 expression with elevated forkhead box P3, transforming growth factor- beta , and interleukin-4 mRNA levels. J Infect Dis. 2007;195(6):870-8.

32. Caramori G, Lasagna L, Casalini AG, Adcock IM, Casolari P, Contoli $\mathrm{M}$, et al. Immune response to Mycobacterium tuberculosis infection in the parietal pleura of patients with tuberculous pleurisy. PLoS One. 2011;6(7).

33. Hanekom WA. The immune response to BCG vaccination of newborns. Ann N Y Acad Sci. 2005;1062:69-78.

34. Wang J, Ioan-Facsinay A, van der Voort EI, Huizinga TW, Toes RE. Transient expression of FOXP3 in human activated nonregulatory CD4+ T cells. Eur J Immunol. 2007;37(1):129-38.

35. Pillai V, Ortega SB, Wang CK, Karandikar NJ. Transient regulatory T-cells: a state attained by all activated human T-cells. Clin Immunol. 2007;123(1):18-29.

36. Wallgren A. The time-table of tuberculosis. Tubercle 1948;29(11):245-51.

37. Poulsen A. Some clinical features of tuberculosis. 1 incubation period. Acta TubercScand.1950;24(4):311-46.

38. Larson RP, Shafiani S, Urdahl KB. Foxp3(+) regulatory T cells in tuberculosis. Adv Exp Med Biol. 2013;783:165-80.

39. Campbell DJ, Koch MA. Phenotypical and functional specialization of FOXP3+ regulatory T cells. Nat Rev Immunol. 2011;11(2):119-30.

40. Suffia IJ, Reckling SK, Piccirillo CA, Goldszmid RS, Belkaid Y. Infected site-restricted Foxp3+ natural regulatory $\mathrm{T}$ cells are specific for microbial antigens. J Exp Med. 2006;203(3):777-88. 